\title{
Fundamentos semióticos para la construcción de un país imaginario: escritura, pintura y mestizaje estético en la obra de Eugenio F: Granell ${ }^{\star}$
}

*Estando este artículo en proceso de revisión, me llega la noticia del fallecimiento en Madrid de Eugenio F. Granell. Que este artículo sirva como sencillo y sincero homenaje a su recuerdo.

JaVier HerRera-NavarRo

Filmoteca Española - Madrid 


\section{Resumen}

La vida y el trabajo del surrealista español Eugenio Granell (19122001), recientemente fallecido, caben perfectamente en una investigación de semióptica visual: el nascimiento y el proceso de un mundo y un país imaginario, a que llamamos Graneland, pueden ser sustanciados, dibujados y creados a través de una combinación original de signos gráficos, pictóricos y escritos, capaces de crear una historia y una sociedad presidida por un humanista dispuesto a integrar culturas distintas.

\section{Palavras-chave}

Granell, surrealismo, semióptica visual

\section{Abstract}

The life and work of the Spanish surrealist Eugenio Granell (19122001), recently deceased, perfectly suit a research on visual semiotics: the birth and process of a world and an imaginary country we call Graneland can be substantiated, designed and created through an original combination of graphical, pictorical and written signs. This combination is capable of creating a history and a society presided by a humanist who intends to integrate different cultures.

\section{Key words}

Granell, surrealism, visual semiotics 


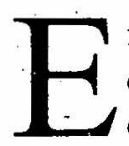

$\mathrm{n}$ un trabajo reciente sobre Granell (Herrera-Navarro, 1995) dedicádo à su primera época, la que comienza con el forzado exilio y concluye con su traslado a Nueva York en 1957, intentaba, desde una perspectiva genética, profundizar en su visión del mundo buscando las huellas figurativas a partir de las cuales poder reconstruir los principios rectores de su idioma (pues lo primero que destaca en su obra, acaso como en cualquier auténtico surrealista, "es esa "floración espontánea e individual" que Baudelaire(Baudelaire, 1998, p. 155) creía intrínseca a todo espíritu revelador y que se manifiesta en un tipo de expresividad muy personal y, como consecuencia de ello, en una forma perceptible apenas antes conocida). Así vimos que la personalidad y la originalidad de Granell -lo que podríamos llamar su cosmovisión- comienza a construirse sobre tres pilares básicós, enraizados cada uno de ellos en tendencias antropológicas e imaginarias (en el sentido desvelado en su día por Gilbert Durand, 1983) de hondo calado, las cuales, si bien surgidas simultáneamente en el mismo tiempo cronológico, mantendrían entre sí, como si füeran trillizos, un ciertó orden de prelación, genéticamente hablando.

El primero sería de origen estrictamente piçtórico y atañería à la línea que, iniciada en el cubismo picassiano, desemboca en la forma quebrada y desencajada de algunos surrealistas, como Lam, Matta y Gorki así como en la peculiar grafía asimétrica de Chirico, y que tiêne en la máscara y en las cabezas de indios su principal argumento y campo de aplicación. El segundo, directamente imbricado con el anterior, procedería del descubrimiento y posterior asimilación de las culturas indígenas mesoamericanas, en especial la nahua, que introduciría en él los aspectos primitivistas, populares y decorạtivos propios de un lenguaje en el que no existe separación entre la imagen visual y la escritura. $Y$, finalmente, el tercero sería la consecuencia del 
propio bagaje cultural, la tradición española y europea, humanista, barroca y judeo-cristiana, y que manifestaría en el sentimiento teatral y humorístico que invade su obra. Así pues, resumiendo: la adquisición, por imitación, de un lenguaje pictórico adscrito al surrealismo y, por asimilación, de un lenguaje ornamental primitivo con un status especial concedido a la imagen (en lo que ambos lenguajes, el culto y el popular, coinciden), en el seno de una tradición cultural específicamente española, es lo que conforma, en nuestra opinión, la peculiar síntesis que se opera en Granell y que impide que su personalidad pueda ser sometida a análisis según las normas de fragmentación y disociación, siempre ahistóricas, que suelen ser más usuales en el lenguaje utilizado hasta ahora por sus críticos. ${ }^{1}$

Por el contrario creemos que su figura se presta como pocas, a partir de esas premisas, para una consideración integral de la personaartista que pueda ser coherente (incluídas las contradicciones) tanto con la perspectiva baudeleriana como con el movimiento surrealista al que se le adscribe. Es, creemos, a partir de dicha visión totalizadora y unitaria, al tiempo que respetuosa con el más acentuado individualismo, desde donde creemos posible su inserción dentro de la historia del arte español del siglo XX, una historia que debe superar los ismos hasta ahora dominantes (sobre todo el historicismo, pero también el sociologismo y el psicologismo) a fuer de desempolvar la gran cantidad de tópicos escolástico-académicos en que se fúndamentan buena parte de sus argumentaciones. A conseguir ese propósito, rescatándole desde una posición de coherencia histórico-crítica entre el método y el objeto de estudio, va encaminado el presente ensayo que se proyecta sobre el ciclo vital del artista más amplio y fecundo, el de su estancia en los Estados Unidos de América, y que ocupa cronológicamente desde 1956, el año que marca el final de su estancia puertoriqueña y preludio de su dilatada estancia neoyorquina, hasta 1985, año de su regreso triunfal a España. (Baudelaire, 1988, p. 115).

\footnotetext{
1. Apesar de la abundante bibliografía que sobre Granell se ha publicado después de su regreso a España creemos que aún falta la monografía que sitúe la especificidad de su obra desde una perspectiva histórico-artística: esa es nuestra intención por eso dejamos para otra ocasión propicia el análisis del período que abarca desde 1975 hasta nuestros días.
} 


\section{En pos de Granelandia}

Uno de los argumentos más tópicos del historicismo en relación con el arte español del siglo XX -y que es uno de los más socorridos, junto al de la fragmentación antes aludido, a la hora de enjuiciar la obra de Granell- consiste en asignar a un artista, partiendo de una verdad que se cree incuestionable: su pertenencia a un movimiento o estilo, y en base a una serie de equivalencias, las características propias de dicho movimiento o estilo; por ejemplo: si Granell es surrealista, todas (o la mayor parte de) las características del surrealismo son aplicables a Granell. De ahí se deduce un tipo de razonamiento generalista y abstracto, normalmente realizado a través de asociaciones de ideas, analogías o imágenes poéticas, que yendo del todo (surrealismo) a la parte (Granell) intenta ver en la concreción en éste de los rasgos definitorios y más característicos de aquél, cual si el individuo fuera un hijo biológicamente gestado y parido por el ente superior y que, por ello, sólo encuentra su razón de ser -su explicación- en tanto en cuanto existe esa relación de dependencia. Razonamiento que si bien no resulta falso en un principio (y de hecho puede iluminar el conocimiento de un artista sobre todo en sus comienzos), sí puede resultar erróneo -y de hecho lo es- cuando se pretende sea el único discurso válido susceptible de justificar toda la trayectoria o la personalidad de un artista. Nosotros, sin despreciar dicha perspectiva, creemos necesario comenzar por una desmitificación de dicho tipo de razonamientos y para ello preferimos situarnos en la línea de pensamiento establecida por Baudelaire antes apuntada cuando niega la posibilidad de la idea de progreso en el orden de la imaginación:

El artista no sale más que de sí mismo. No promete a los siglos venideros más que sus propias obras. No da seguridades más que de si mismo. Muere sin hijos. El ha sido su rey, su padre y su Dios. (Baudelaire, 1988, p. 115).

Partimos, pues, de la base de que Granell ha sido quizás en exceso "explicado" y "visto" por la crítica española reciente más en 
función de sus contactos con los padres ortodoxos del movimiento, Breton, Duchamp, Péret y compañía -importantes sin duda, nadie lo niega- $\mathrm{y}$,consiguienteménte, aplicándosele las imágenes poéticas a ellos asociados, que en función de su específica, y riquísima, personalidad de humanista proteico capaz de inventar un mundo, un lugar imaginario, acaso un país, desde luego que sí una geografía, poblado por infinidad de criaturas y sometido a sus propias -fantásticas e idílicas- leyes. Para divisar ese lugar, por nombre Granelandia, y viajar por él hay que purificarse primero desprendiéndose de todo cuanto haya sido dicho y publicado desde esa perspectiva bienintencionada pero a todas luces contaminadora, y con ojos ingenuos, de niño que aún cree en los Reyes Magos, ir atisbando, como una Alicia rediviva a través del espejo, una por una todas las sorpresas que dicha incursión puede irnos deparando.

\section{Primer proceso depurativo: reintegración de la totalidad y vindicación de la dialéctica granelliana}

Que estamos en una época de liberalismo salvaje no solamente en lo económico y que dicho salvajismo "yoísta" (pues se funda única y. exclusivivamente en el imperio del yo y la satisfacción de sus necesidades más primarias) se ha apoderado del individuo hasta el punto de influir decisivamente en el pensamiento crítico bajo la forma del indeterminismo, la última versión del racionalismo occidental, no precisa de comprobación; que la moda por el fragmento y el discurso deconstructivo han arrinconado por abstractas e idealistas las construcciones teóricas de índole globalizadora es igualmente otro hecho constatable, que no por evidente está por ello exento de caer de su pedestal en cualquier momento; que él hombre -el individuo- jamás ha estado más descuartizado, fragmentado o partido en mil pedazos como ahora y no sólo psíquicamente (los maníacos que cuartean a sus víctimas son la más firme y salvaje expresión de esa realidad íntima que aflora al exterior de modo brutal) es otra constatación respecto a la cual el arte no es sino la simple sirvienta de esa cámara de los horrores en la que se ha convertido la vida.

Granell no resiste las aproximaciones popperianas que bajo la bandera del sentido común suelen esconder las múltiples añagazas de la desintegración y del caos que deviene tras las "atractivas" aperturas del 
sistema: su universo es cerrado lo que no quiere decir ni hermético ni aislado ni resistente al aporte de riqueza; es, no obstante, dialécticamente abierto en cuanto que'se sabe finito, partícipe de una totalidad mucho más amplia, de una unidad única y con tendencia a la armonización, sin exclusión de las tensiones, de todas y cada una de las partes, como en el niño, en el primitivó o en el taoísmo ${ }^{2}$. Y de ahí que lo que puede parecer contradicción, entre la quietud y la tensión, intenta resolverlo de la única manera posible: sabedor de que la civilización occidental desintegra la unidad y la totalidad del ser humano-incluído él- enfocará su vida en un continuo discurrir hacia la reintegración de los elementós anteriormenté désmembrados. De ahí que su trabajo sólo pueda entenderse desde la dialéctica superadora de esa desintegración básica el pécado original-con la que el ińdividuo viene al múndo: én eso coincidè con Breton y el surrealismó. El mismo ha explicitado esta línea de pensamiento con las siguientes palabras:

Breton creía y otros muchos'surrealistas también, como yo, que es a causa de la pérdida de la integridad total del hombre original, que mantienen el niño $\mathrm{y}^{\dagger}$ los indivduos de $\operatorname{los}$ ilamados pueblos primitivos. Para el hombre primitivo no hay.esas diferencias que se han inventado entre el alma y el cuerpo, el sueño y la vigilia, la materia y el espíritu, etc. Ellos contemplan la vida y el mundo en su tótálidad. Los animales, la vegetación y toda -la vida cíclica y material del individuo conforman un todo homogéneo, como pasa con el niño. Yo creo que es una gran pérdida, seguramente producto de la educación excesivamente racionalista que recibimos en nuestros primeros años... Crẹ que el gran culpable de la acentuación de esta división del ser humano en dos partes, proviene del imperio del racionalismo en el Renacimiento italiano (Granell, 1986, p.26).

2. Pero también hay que entender ese señuelo de totalidad en la indistinción de géneros -es otra de las operaciones de la óptica fragmentaria- y no en la diferenciación entre ellos como hasta ahora se ha hecho al tratar su figura. Si él mismo afirma que literatura y pintura son una misma cosa (Cf. Granell, 1986). Entrevista con César Antonio Molina; en Catálogo La Coruña 1986, p.26) no hay razón de ser para separar cada una de sus facetas. Dicho criterio pensamos es el único válido en el momento presente para encarar desde la historia del arte la extraordinaria complejidad de los fenómenos histórico-artísticos en el periodo que se avecina. Véanse al respecto las tesis, que suscribimos en su totalidad, Estèla Ocampo (1984;1989). 
Es, pues, Granell, en una primera panorámica de conjunto, un intérprete crítico del racionalismo europeo coincidente desde sus inicios con la visión surrealista del hombre y del individuo, tendencia que se manifiesta ya en su primera época, si bien todavía de forma rudimentaria, en là triple dimensión, artística, antropológica y cultural, que adquiere su obra àl recoger y luego ásimilar los tres tipos de enseñanzas que incorpora a su personalidad. La primera de ellas, de procedencia estrictamente pictórica como vimos (las lecciones de Picasso, Lam, Matta y Chirico en cuanto a forma y punto de vista), pasará enseguida a formar parte de su peculiar lenguaje y en su progresiva disolución irá conformando y delimitando los confines de los otros dos territorios (el antropológico, decorativo y popular de la cultura indígena y el literario y cultista de la historia cultural española) hasta el punto de que cada uno de ellos, encabalgándose en el precedente, obtendrá por un lento proceso de metamorfosis un protagonismo exclusivo en las siguientes etapas de su trayectoria. Hay que entender, en consecuencia, el período primerizo como la matriz, el núcleo generador que alimenta el posterior deslizamiento hacia una mayor claridad de su propuesta. Pues entendemos que ya desde este primer momento Granell, lejos de dejarse llevar en brazos del azar, tiene en tanto que ser humano-artista un proyecto más o menos definido -más bien podríamos decir intuído, aún en fase embrionaria, es lógicoque pasa necesariamente por el logro de una síntesis entre lo que lleva y lo que encuentra, encrucijada en su trayecto en la que se enfrentan, se mezclan y dialogan dos culturas (no se olvide su condición dramática de exiliado), y que le llevará, tras la siempre dolorosa operación de síntesis, a la invención simultánea de un idioma -el granellano(Pierre, 1990,pp.29-45)- y de una cosmología y una cartografía apropiadas (Molina, 1990, pp.65-73) tras las que fundar su gran sueño y proyecto: la construcción de Granelandia.

\section{(A modo de paréntesis: un excurso-breve-por el tiempo)}

Pero antes de adentrarnos en sus atractivos confines conviene que perfilemos de antemano dentro de ese gran período en el que nos 
encontramos, y que podríamos llamar neoyorquino o metropolitano, cuáles son los momentos, claramente delimitados, por los que ha de discurrir nuestra andadura. Aquí, en estos casi treinta años, lo primero qué resalta es que no hay grandes hitos biográficos que pueden marcar una distinción formal, estilística o simplemente idiomática (el trayecto de Granell es de una estasis casi oriental, sin sobresaltos) sino que es ésta, la propia dinámica interna de la forma que diría Wölfflin, quien parece ir marcando el compás de la diferenciación en un antes y un después, pero nunca de manera nítida, pues hay siempre preludios $y$ presentimientos de lo porvenir como en las tejas de un tejado entre los diferentes momentos que van emergiendo dentro de una misma línea. figurativa e incluso los rasgos que van quedando relegados tampoco desaparecen del todo sino que en un lento proceso de pérdida de protagonismo se van diluyendo como una vida que se apaga pero $\sin$ agotarse del todo: en cualquier momento pueden reaparecer para poner en solfa la lógica de la evolución. Teniendo en cúenta esas particularidades podemos situar hacia 1974 un leve trazo de separación entre la manera que se inicia en 1956, marcada por los paisajes mágicos y geológicoś, y la manera más típica del granellano y de Granèlandia que llegaria hasta nuestros días, período este último que es el más estudiado y conocido y que ahora sólo podemos dejar entrevisto.

Cosmología y geología: la insularidad y lo magmático, fundamentoside la poética mestiza

Para aproximarse a Granelandia aún queda un largo trecho: por recorrer y no precisamente placentero. El hombre que ha visto ya cómo su cuerpo y su mente se fragmentan y se parten por la mitad, fruto de la tesitura dramática del exilio -imagen de la derrota- y del primer contacto con una vida y unas costumbres opuestas -insulares-. , sospecha que de su impedimenta occidental y culta sólo podrá conseguir un sentimiento cada vez más acentuado de extrañeza respecto de sí mismo y los demás. El hombre, ya en estado adulto, ansía la felicidad perdida, el equilibrio que no hace múcho existía entre él y el mundo, la unidad que mantenía con las cosas que le rodeaban: recuerda que todas cobraban vida y a veces hasta parecía que la luna le perseguía 
por las calles y corría y corría azorado para ocultarse de su mirada curiosa. A él de niño -constata- le pasaba algo parecido a lo que ahora ve en el indio caribeño y un buen día seguro que se pregunta: ¿porqué no seguir viendo el mundo con los mismos ojos ingenuos de la niñez $o$ del indígena? En esa pregunta, a nuestro entender la más importante que un artista podía hacerse para captar la esencia de la vanguardia, y en su respuesta afirmativa se encuentra el gran paso de Granell que dará comienzo a su singular aventura de retorno a la inocencia perdida, de reconstrucción de la unidad, de reintegración en la totalidad.

Ello supone un viaje intrauterino hacia un nuevo lugar aún insospechado (todo retroceso es siempre luctuoso) para volver a nacer, un encontrarse de nuevo con el caos genuino e informe al que poco a poco en su tosquedad hay que ir moldeando y dando forma: el principio de orden que se contrapone al caos inicial y perfila su cosmogénesis es la isla con la infinidad de símbolos, todos certeros, a ella asociados. La insularidad caribeña, al contener en sí y en armonía los cuatro elementos fundamentales (tierra firme rodeada de agua con vientos impetuosos y vísceras fogosas en su interior), se convierte en el punto de arranque a partir del cual poder diseñar la vida nueva - la nueva visión, la mirada del niño y del indio - y así conectar y unir los diferentes mundos (celéstial, terrestre, acuático y subterráneo) en un todo homogéneo y armónico. La concreción de los principios que han de regir en esè lugar imaginario se condensan en el libro Isla cofre mítico publicado en 1951 y en el que, a modo de paráfrasis del libro de Breton y Masson Martinique charmeuse de serpents publicado tres años antes, la isla cobra una triple dimensión simbólica en virtud de las asociaciones que establece, primero, como punto de conexión entre el mito antiguo y el nuevo relativo al descubrimiento de América, primero por Colón y ahora por Breton; segundo, en su identificación con el surrealismo, entendido como una isla salvadora en medio del naufragio colectivo de la civilización, para finalmente, coincidir simbólicamente con la mujer y el cofre, tabernáculo, sancta santorum y primer objeto de la nueva mitología. Dicha triada salvadora y propiciatoria tiene como último objetivo e ideal a alcanzar la libertad absoluta entendida como fundamento esencial del humanismo que pretende allí ser construído ("Encontrado de nuevo su autenticidad, el ser humano hallará en sí 
mismo la clave, la llave que habrá de permitirle abrir el arco de acceso a la isla de la libertad, trono de la mujer niña anunciada por Breton"). ${ }^{3}$

La isla, que es ya armonía entre el pasado y el presente, cofre ${ }^{4}$ intimo de la nueva redención humanista, belleza de mujer, la plataforma ideal para conseguir la libertad, comienza a poblarse, primero, de una particular zoología, esa "fauna futura" (en el decir de Péret ${ }^{5}$ ), realizada en Puerto Rico entre 1951 y 1956, que combina figuraciones humanas, vegetales y animales con fragmentos de objetos del mundo artificial y mecánico dentro de la línea iniciada por el El Grand Verre de Duchamp (a quien conoce en 1952 durante un viaje a Nueva York) y tiene como arquetipo al Pájaro Pi, protagonista de vuelos tanto diurnos.como nocturnos, hijo predilecto de una saga de aves de alto copete (además de otro que sigue siendo flor hay uno estelar, otro de oro y de la noche e incluso un ave crepuscular), a través del cual Granell pretende simbolizar tanto sus ansias incontenibles de libertad como (acaso) el principio pi-tagórico rector que ha de regir los secretos de la naturaleza dentro de su isla:

Todo se renueva. Todo continúa. Todo se repite. Todo sigue igual. El ciclón es ciclón, el volcán terremoto, la selva es el río, el rio es el volcán, el día es el ciclón, la noche ya no es noche o si lo es aún. Al manejar su máquina, el Pájaro Pi se extasía. Queda envuelto en un torbellino de visiones que juntan en los aires las cúpulas urbanas de Coria, Burgos, Guanajuato, Soria, Manila, Charleston, Valparaíso, Lima, Bogotá y Jerez de la Frontera vacio de dentistas y gitanos. Reina el más estricto orden lógico. Una vez fecundado el Pájaro Pi, que es pájaro-nube, que es pájaro-lluvia, que es pájaro-piedra, que es pájaro-espejo, su varonil palmera capital riega las tierras. La maquinaria de hojas, raíces, aves y luces

3. Utlizamos las primera edición puertoriqueña de 1951 de editorial Caribe. La cita en pág. 61.

4. Bachelard (1992, pp.115-119) lo relaciona acertadamente con la "necesidad de secretos" y con la "inteligencia del escondite".

5. Creemos hasta el presente uno de los mejores, si no el mejor, acercamiento a las claves del Granell de esta etapa primeriza. El título original "A la hauteur d'un cri" publicado en 1954. Reproducido íntegro en Granell. Catálogo Mapfre 1989, p.28 
no hace más que engullir crepúsculos y auroras.

Si aletea, el Pájaro Pi abanéa el volcán.(Granell, 1990, pp. 384-392)

Es el elemento aéreo, tal y como ha apuntado Guigon (1996), el dominante en un principio dentro de su cosmología, pero he aquí que en vez de producir sus criaturas dentro de los cánones de pureza regidos por dicho elemento tan sólo acepta de ellos el concepto - pájaropara bañar después su morfología de las más variadas impurezas, anticipando mediante esa operación uno de los fundamentos de la simbiosis lingüística en la que ha de basarse su poética mestiza. Hay ya en esos pájaros espectrales y cósmicos una tendencia a abarcar la totalidad como el niño, el ingenuo o el primitivo y en ello va anticipando en forma de preludio (la notación musical en Granell es también clave en su ordenamiento) ese proceso de regresión hacia el origen que va a ser la constante de su inmediato devenir. Poblado el aire, omnipresente de pura realidad el agua, sólo hace falta organizar la otra dualidad: roturar la tierra, descubrir el fuego.

$\mathrm{Y}$, en efecto, a partir de 1956 comienzan a reaparecer pero de otra forma más elaborada los signos gráficos que de una manera aún tímida nacen con Isla cofre mitico ya en forma de escama serpentina, ya en forma de carácter caligráfico, de nervio folicular o incluso de alfabeto telegráfico, y que en esta época se van a convertir (nunca mejor dicho) en matrices sintácticas de la escritupintura. Con dichos elementos Granell va diseñando el paisaje terrestre de la insularidad, un paisaje antinatural repleto de insinuaciones agrícolas -la tierra como madre y principio de la vida- pero que acaso por el propio poder de sugerencia de los signos en su agrupación y dependencia.mutua va poblando de apariciones fantasmales y de seres inquietantes que solo anidan en la imaginación enfebrecida de su hacedor: las obras (pueden citarse El rey y la reina buscan a Marcel Duchamp, El nacimiento de los pájaros, Peinador de lunas todas ellas de 1957) progresan a partir de un toque en apariencia casual que se encabalga con el siguiente y este a su vez con el siguiente formando unos ritmos regulares y disonantes sin ningún orden preestablecido; sin embargo, ese automatismo e improvisación es siempre aparente, la propia metamorfosis del signo va creando las formas y a pesar de que puede 
hablarse de un cierto esquematismo abstracto -se encuentra no lo olvidemos en un proceso de regresión y esto le hace encontrarse con las raíces del lenguaje pictórico- existe no obstante un principio regulador que controla el proceso dentro de unos ciertos límites, aquellos que impone la estructura serial, puntual, aditiva, a base de yuxtaposiciones (muy similar a la escritura pentagramática que durante esa época realiza la música por ejemplo de Varese), en el seno de un marco en el que el horror vacui, similar a la incontinencia decorativa del barroco criollo, es tan dominante que la vista se ve abocada a una borrachera cromática dificilmente controlable. Aquí en estas obras es en donde su trabajo conecta más con el arte y la artesanía popular, en especial la tapicería, tanto del ámbito caribeño, recién abandonado, como del existente en el llamado "folk-art" estadounidense, uno de cuyos componentes esenciales es el formado por las culturas marginadas procedentes de la emigración hispano-latina y por los restos del indigenismo de las primitivas tribus de la época pre-hispánica ${ }^{6}$. Su trabajo va adquiriendo cada vez más una dimensión enciclopédica a la par que universalizadora pues ya es capaz, amén de la conocida coexistencia entre el pintor y el escritor, de aunar la inquietud del coleccionista con la mirada del antropólogo ${ }^{7}$, espíritu interdisciplinar ciertamente pionero que muy pocos han sido capaces de resumir en su persona.

Un año después, 1958, dicha tendencia se acentúa al aparecer en liza (su concurso era necesário para dar verosimilitud al proyecto definitivo: las obras que inician la tendencia pueden ser El incendio de la Torre de Babel o Arquitecto mágico) el elemento devastador y purificador: el fuego volcánico que inunda con sus magmas

6. La influencia de los tapices atestiguada en Granell (1994, p.338): “Hay un elemento colorístico que mi me impresionó mucho cuando lo vi en América por primera vez: esos tapices de plumas, hechos por los indios, que hay desde Perú hasta Méjico. Esas escamas que tú dices, esas plumas que yo recuerdo, pueden estar en el origen de ese tipo de cuadros míos".

7. La faceta antropológica de Granell, básica para entender su obra, está certificada de múltiples maneras. Véase su conversación con Ruiz (1994,.pp. 340-341). En cuanto coleccionista, faceta complementaria, de la anterior véase el catálogo de su colección publicada por la Fundación que lleva su nombre en 1995 con textos importantes de Javier Ruiz, José Pierre y Luis Mombriedo. Tampoco puedo resistirme a la definición que da Walter Benjamin (1987, p.55) del niño desordenado y que creo leva a Granell como anillo al dedo: "Cada piedra que encuentra, cada flor arrancada y cada mariposa 
incandescentes los surcos de la tierra nutriente, asola tos campos de cultivo agrícola, asfixia a là fauna y devuelve a la geología ${ }^{8}$ a su estadio primitivo, dual y cóntrapuesto, en el que la topografia aún no puede evolucionar a la cartografia: los deslindes geomorfos aún presentes, por ejemplo en Teresa de Avila se pregunta si volver o no a Toledo de 1961, El caballito de la reina africana de 1963, van desapareciendo poco a poco bajo el peso de la lava y de la distorsión magmática para ir siendo borrados por la exhuberancia del desorden; por el anuncio del caos. Tal parece que las gemas del cofre hubieran abandonado su intimidad de siglos por la innoble acción de un pirata avariento y desbocadas, profanado su secreto, se hubieran lanzado a la intemperie de una lucha sin cuartel con la banda de profanadores. Si antes aún cabía la esperanza de poder situarse en el filo del abismo ahora las llamas y las hogueras rojigualdas de las fraguas han anulado cualquier atisbo de profundidad y de coordenada espacial (tal y como puede apreciarse en Las lunas son siempre distintas de 1962 o en La gran inauguración de la plaza de toros ya de 1964): el arabesco que delimita las fronteras del caos se contorsiona y se mezcla en el atanor de Vulcano con tal virulencia en su propia imagen que el cuadro queda reducido a una acumulación informe de brasas (no es casual que en 1964 aparezca el libro de Tarnaud, 1964$)^{9}$ que hasta parecen quemar la propia superficie del lienzo. Merece la pena detenerse un poco en las obras que marcan la evolución entre las obras anteriormente citadas y las que suponen la culminación de la tendencia, la serie del Bandido de Córdoba, para ver

capturada son ya, para él, el inicio de una colección, y todo cuanto posee constituye una colección sola y única. En él revela esta pasión su verdadero rostro, esa severa mirada india que sigue ardiendo en los anticuarios, investigadores y bibliófilos, sólo que con un brillo turbio y maniático. No bien ha entrado en la vida, es ya un cazador. Da caza a los espíritus cuyo rastro husmea en las cosas; entre espíritus y cosas se le van años en los que su campo visual queda libre de seres humanos. Le ocurre -como en los sueños: no conoce nada duradero, todo le sucede, según él, le sobreviene, le sorprende. Sus años de nomadismo son horas en la selva del sueño... Ya hace tiempo que el niño ayuda a ordenar el armario de ropa blanca de la madre y la biblioteca del padre, pero en su propio coto de caza sigue siendo aún el huésped inestable y belicoso". Toda aproximación a la obra de Granell que no tenga en cuenta esta doble perspectiva siempre será fragmentaria e incompleta, de ahí que sea preciso volver en otra ocasión sobre el teria.

8. Las fuentes directas de estas formas han sido recoconocidas por el propio Granell en el paisáje americano y en sus frecuentes visitas de niño al Bosque de la Condesa de Santiago de Compostela. Véase Granell (1994, p.339).

9. Véase el catálogo de la exposición Islas y brasas. Museo de Teruel, 1993. 
cómo va progresando el sistema constructivo de la cosmología granelliana y cómo a la par se manifiesta su proceso creativo.

En primer lugar se observa una progresiva complicación hacia la representación del anti-vacío así como que la plenitud expresiva se ha conseguido, a base no de horror, sino de "terror vacui", hechos que hay que asociar al logro de la máxima regresión hacia el espíritu del primitivo, del niño y del ingenuo. ${ }^{10}$ También se aprecia que en el discurso intermedio que va desde La gran inauguración...hasta la serie del Bandido se va percibiendo, tanto en cuadros completos ( $E l$ palacio flotante en algas y corales de 1963, Tifón y Bayaderas del año siguiente) como en partes de otros (desde Remembranzas de un gaitero y El viaje del fantasma de 1965 hasta la serie completa del Bandido), la tímida presencia, a modo de oasis reparador o de contrapunto atonal con la obsesión dominante, del azul sinuoso del océano o la infinita policromía de la botánica subacuática, como si hubiera que descansar de tanto caos y fuego y el principio estructurador necesitara un punto de equilibrio en tan violenta orgía. Por otra parte es curioso constatar que a medida que avanza esa regresión depurativa hacia el nuevo origen, hacia el "volver a nacer" en que hemos resumido todo su proceso de cosmogénesis ( $\mathrm{y}$ que creemos llega a su punto cero de no retorno precisamente en este año de 1967), brotan con mayor poder de sugerencia las insinuaciones figurativas que salen como por arte de magia de la propia estructura magmática; es como si el proceso de metamorfosis se originara según la ausencia o presencia de los cuatro elementos que conforman la materia: si no hay atmósfera porque no hay horizonte y el agua -como hemos visto- apenas asoma, todo se resuelve en una lucha fratricida entre la tierra y el fuego, elementos contrapuestos y al tiempo complementarios a partir de los cuales las formas en su bullir y continua regeneración van sugiriendo los asuntos,

10. El mismo corrobora esta impresión cuando afirma: "A ese tipo de cuadros yo los llamé siempre Paisajes Mágicos. Yo los asociaba con reminiscencias de los cuentos infantiles, donde hay paisajes mágicos. Hay una mutación constante de esos paisajes, que crecen o decrecen dentro del cuento, que se transforman en otra cosa; de repente son cabezas humanas... Esos cuentos son mágicos siempre, y esos procesos de transformación te quedan, no los puedes guardar para ti, son "parte de tí mismo". (Cf. Ruiz,1994, p.339) 
los temas, cada vez, de nuevo, más perceptibles que antes y, por supuesto, ya alejados de la tentación espontaneísta y abstracta. ${ }^{1.1}$

Síntoma igualmente verificable de que se ha llegado al punto de no retorno es la metamorfosis cromática, que va abandonando los colores terrosos y llameantes, marrones y rojos con mayores o menores dosis de ocres, hasta recuperar los tonos blancos y azules asociados al cielo y al mar, los elementos más sutiles y poéticos. La serie del Bandido de Córdoba sigue siendo elocuente al respecto: si en La cueva del tesoro el principio magmático es omnip

respecto: si en La cueva del tesoro el principio magmático es omnipresente, en Bodegón nupcial.y en Verdadero retrato dicho principio, aún siendo dominante, ya se combina con los azules acuáticos y aéreos hasta desembocar en Las bodas donde la tendencia se invierte hasta el punto de suplantar por completo el monocromatismo äzulado a los colores tierra y füego. Al mismo tiempo, creemos que esta serie, y dentro de ella este cuadro, actúa dentro de la trayectoria de Granell como final de una etapa y comienzo de otra, pues a partir de él parece remitir el terror vacui y la exhuberancia decorativa, el proceso de recuperación de la figura compuesta de tales ingredientes magmáticos se normaliza al tiempo que aparecen los primeros componentes específicos de la humanidad típica de Granelandia: los cuerpos gelatinosos y blandos totalmente deformes con piernas "figuradas"12 por fragmentos de objetos enigmáticos.

11. Hay que tener en cuenta que todo ese proceso tiene lugar en el momento de máximo protagonismo hegemónico del expresionismo abstracto; el hecho de que Granell se mantuviera al margen es indicio de que su proyecto es de otra índole: acaso él también se conciba como una isla en medio de la vorágine del mercado: pudo haber ganado dinero, dice, pero su proyecto es un proyecto personal, no arraigado socialmente, sino lo justo para sentirse protegido y poder. desarrollar libremente sus inquietudes..(Cf.Granell, 1986, p.26)

12. El componente "figural" en Granell responde a la acepción más auténtica que va implícita en dicho concepto: hacer pasar a una cosa como si fuera:lo real. Desde ese punto de vista su obra recoge la tradición retórica y conceptista del barroco español, léase Gracián, aspecto éste que ha de ser visto en mayor profundidad. 
Del bandido de Córdoba a la paloma de Uccello: los cimientos de Granelandia

Lo que hemos llamado "estilo magmático" no es en realidad sino la elevación del signo gráfico-decorativo, fundamento de sus primeros balbuceos en el procesóde regresión hacia el reino de la totalidad perdida que estamos viendo, hacia el lugar imaginario en el que llega a confundirse con el contenido que su propia forma va generando. ${ }^{13}$ Desde este punto de vista Granell se ha servido en esta etapa del automatismo psíquico típico del surrealismo de forma muy similar a como se manifiesta en los "dibujos telefónicos" (como, por ejemplo, los de Luis Gordillo), en los cuales la mano sigue fielmente el decurso del cerebro y va llenando y rellenando de forma gráfica; atendiendo a la particular tesitura mental de cada uno, el espacio del papel que se tiene delante: las formas así generadas llega un momento que van creando sus propios significados, haśta el punto de poder llegar a convertirse en temas, en contenidos de sí mismos. Esa tautología, que es prototípica de la abstracción más racionalista, al combinarse con la técnica surrealista antes aludida, va derivando hacia una peculiar síntesis que expresa en su carácter inédito un avance en lo que respecta al alumbramiento de lenguajes mestizos, híbridös y superadores de los purismos originarios; àsí, lo que comienza siendo deuda respecto al movimiento, estilo, lenguaje o téndencia grupal o colectiva, acaba por definir, en los casos como el de Granell, un nuevo yo, una nueva personalidad que, teniendo la riqueza de los lenguajes de origen, los proyecta hacia una dimensión inédita que sé trấnsmite a través de ese nuevo yo que ha sido alumbrado.

Cabría hablar aquí, en èsta etapa, de encefalograma del espiritu en tanto que se revelan -creemos- en esta obra las tesituras biógraficas y autobiográficas por las que pasa su hacedor, primordialmente cabría entender la trayectoria antes analizada como una especie dé desahogo y catarsis (no podemós olvidar la sintomatología del "estierro y del exiliado en su caso) del recuerdo de España y sus vivencias de la Guerra Civil,

13. Las tesis más teóricas de Francástel reunidas en su obra (1969), en cuanto ä la gestación, desarrollo y mutaciones de los órdenes imaginarios implicitos en las construcciones plásticas son perfectamente adaptables a la obra de Granell. 
expuestas por ejemplo literariamente en La novela del indio Tupinamba y luego en su otra novela, Lo que sucedió, y su paulatina evolución hacia una cierta normalización tal y como se concreta en la presencia sucesiva de su obra en Madrid durante los años 1964 y 1967, coincidiendo con los primeros años de apertura del franquismo, preludio de su primer reencuentro físico de 1969.

Así pues Granell no es aquí en 1967 sino una proyección de una nueva individualiadad que ha re-nacido a partir de las tensiones anteriormente provocadas por ese proceso de retorno a la infancia que ha provocado el asentamiento de su cosmología y su geología, de su fauna, su botánica y de su paisaje: ahora ya sólo falta que comience a crear la humanidad que ha de acompanarle en ese lugar imaginario, pero real, que ha re-descubierto. El mismo es consciente de que este período que culmina en ese año es un período de crisis y de que a partir de ahí va a continuar su camino(Granell, 1986, p.26)por la senda dejada en 1956: ciertamente parece que el proceso de bajada a los infiernos ha concluído y que comienza un período de transición en el que ya se van a hacer ostensibles todos y cada uno de los componentes específicos de la escritupintura y de la poética mestiza en la que se inserta. Por eso ya no cabe hablar en nuestra opinión ni de surrealismo ni de abstracción, ni siquiera de surrealismo abstracto sino únicamente de granellano pero en un sentido más amplio que el definido en su día por José Pierre. E1 pintor se acerca aquí al novelista que diseña un lugar imaginario (el Macondo de García Márquez, la Cotiledonia de Cristóbal Serra o la Región de Benet) a ímagen y semejanza de su fantasía y que es correlato simbólico de un país o de un lugar concreto o bien al narrador, muy común dentro de la estirpe galaica (tipo Cunqueiro, Castroviejo o Dieste) o catalana (Perucho, Palol o, incluso, el mismo Pla), que tiende a trascender la realidad cotidiana en base a emparentarla con la mitología, la fábula o la leyenda, creando ambos otro tipo de realidad, mágica o fantástica, cuya estructura creemos está en la base de los recursos fúndadores de su definitivo sistema idiomático, manifestado en su máxima plenitud a partir de 1974, concretamente a partir de otro de sus cuadros más emblemáticos, Paolo Uccello suelta una paloma.

Pero antes, durante los seis años que median entre la serie del Bandido y éste último cuadro, puede distinguirse un período de transición 
en el que todavía dentro de là pervivencia de las formas “escamáticas" las. figuras -ya reconocibles como tales- se van independizando del envoltorio geológico que las envuelve y comiènzan a ocupar los éscenarios, naturales o contruídos, que su creador ha ido diseñando ex-profeso en el interior de . Granelandia, su gran obra, su lugar.

\section{Espacio-tiempo}

En efecto, tras (también del mismo 1967) Pescador en aguas tranquilas, :que puede considerarse tanto una alusión a sí mismo en cuanto eje-autor-cabeza-sujeto-hacedor como también al mismo tiempo una clara anticipación del programa venidero en lo que respecta a su actitud (poco menós qüe viene a decir que "tras la tempestad viene la. calma") y al programa "de incesante actividad creativa que va'a tenér que desarrollar a partir de ese momento (el idóneo para empeźar a recoger ' lo sembrado), su múndo comienza a poblarse dê referencias marinas $\mathrm{y}$ celestes (Joven têmerosa de ser atacada por un bändido de $1968 ; E l$ encuentro profundo de lós reyes del mar de 1970 o El caballo respetuoso con las damas de 1974) $\mathrm{y}$, como consecuencia de ello, de una desbordante libertad cromática, irrespetuosa e irreverente con la lógica náturalista, tal y como puede apreciarse en Los entomólogos escuchan el canto de los pájaros de 1971, El regalo de 1972 o en El maestro felicita a lá bella écuyere de 1973. Esa omnipresente policromía es indicio, sin duda, de una atmósfera limpia y y feliz, como de cuento, en cuyo seno la vida, ya siempre diurna (aunque todaví perviven recuerdos noctámbulos en algún que otro cuadro, como los de "cuatreros"), se intuye como un pacífico discurrir, en permanente idilio con la fiesta y con el juego; por eso, se ha señalado, ${ }^{14}$ como característico de su paisaje la carencia de viento $y$, en consecuencia, la inmovilidad se adueña del espacio en una suerte de nirvana que invierte incluso el proceso lógico del animismo: en vez de animar lo inanimado, dando.vida a lo estático o a lo nohumano él adormece, congela, petrifica lo animado, revelando con ello una contradicción que todo adulto posee en cierto grado por mucho que

$\overline{14 . ~ V e ́ a s e ~ R u i z, ~ 1994, ~ p a ́ g .333 . ~}$ 
intente disimularlò y que èstá anclada en el inconsciente colectivo, a saber: la anulàción de la fantasía por parte de la imaginación, respondiendo con ello, acas o sin saberlo, al tipo de imaginario que tiene su ráíz en la fotografia y en su esencial mecanismo para detener el tiempo. Cuando Granell declara que

el tiempo de la pintura es un tiempo interior, un tiempo detenido. En cada pintura es como si el artista echase al fondo del mar el ancla del tiempo. Pero además, las acciones están en suspenso y se desconoce su consecuencia o su precedente (In: Ruiz, 1994, p. 337),

no hace sino aplicar de modo inconsciente el principio fotográfico de la captación del instante, de ese aquí-ahora que ya para siempre permanecerá, muerto, ${ }^{15}$ como simulacro de algo que existió en un tiempo pero que ya ha dejado de existir: es lo que Frank Popper, ${ }^{16}$ el estudioso del movimiento, definió como "movilidad inmóvil", pues Granell, quiera o no quiera, y por mucho que intente paralizar el paso de un antes a un después el propio proceso de mutación temporal de la pintura en su plasmación física, fiel reflejo de la metamorfosis a que somete a sus imágenes, le coloca en otro orden de realidad - la biológica - contra la que no puede luchar. Es por ello que, al igual que Chirico (al que sin duda más se le parece) y el Picasso del cubismo sintético, el espaciotiempo de la pintura de esta etapa es de orden intelectual, pretendidamente mítico e intemporal, no referido sino a su ausenciá, a una estasis dilatada y prolongada que no quiere acabarse nunca y que sin duda anida y es próducto de la imaginación, una suerte de ideal soñado. Es un mundo, en consecuencia, fantasmagórico, espectral, inanimado, inmóvil, ahistórico o metahistórico, como diría Santos Torroella, ${ }^{17}$ en el que tanto Newton como Einstein son impensables.

Sin embargo ese ideal soñado - producto del espíritu - no se logra del todo porque la lógica racionalista del signo gráfico se le impone y-no tiene otro remedio que recurrir a asideros espaciales que, como en

15. Adoptamos aquí la interpretación que da Barthes (1982) de la fotografia.

16. Véanse sus dos artículos fundamentales $(1965 ; 1967)$.

17. Cf. "Granell y su pintura metahistórica", pp.33-35. 
la pintura barroca española, recuerden que nos encontramos en la tierra y no en el cielo: nos referimos a las tarimas o a los elementos de tramoya teatral que nos remiten a un escenario construido a posta, de ficción donde se desarrolla una trama que es el contenido, el tema del cuadro; una ficción, en suma, dentro de otra ficción, como se ve la misma estrategia de "cuadro dentro del cuadro" que Velázquez aplica tanto en sus obras cumbres como en los "bodegones a lo divino" de su primera época sevillana. ${ }^{18}$

Ese recurso a la tradición teatral española que, como veremos más adelante, es mucho más rico, se complementa también en esta etapa que comienza entre 1968 y 1974 con la recuperación de la visión frontal que se había perdido en la época precedente, dominada por lo que el mismo Granell llama visión perpendicular, y que relaciona su concepción del espacio (la vista desde arriba) con la de los niños y los primitivos:

Mi espacio-afirma - es perpendicular. Yo creo que en mi obra, en toda mi obra, la visión perpendicular domina toda posibilidad de estructura perspectiva. Bueno, la perspectiva no me interesa. Hasta puede ser una perspectiva, pero perspectiva perpendicular. No es la geométrica de que el árbol que está más lejos tiene que ser más pequeño, etc. Puede ocurrir lo contrario.(In: Ruiz, 1994, p. 334)

Así pues, la recuperación de la frontalidad no sería sino una prueba más de ese retorno de ciento ochenta grados hacia el equilibrio perdido en la etapa anterior y que amenazaba con la pérdida definitiva del control sobre sí mismo: por eso ahora para la edificación de Granelandia necesita en cierto modo llegar a un compromiso entre la visión del niño y la del adulto, siempre históricamente condicionada.

18. No puedo por menos que remitirme a las obras fundamentales en este sentido de mi maestro Julián Gállego (1978;1984), capitales para entender ese doble lenguaje del pretendido realismo español. Granell, sin duda, es como veremos, continuador de dicha tradición. 


\section{La metamorfosis como principio constructivo: el bodegón teatral}

Una vez creada la coordenada espacio-temporal con sus respectivos asideros falta por concretar la técnica de creación apropiada a los supuestos teóricos anti-naturalistas, no perspectivísticos y antidinámicos, es decir lo propio de una estructura imaginaria de signo intelectual en la que la imagen se revela y se detiene en el mismo momento en que va floreciendo; hablamos lógicamente de la metamorfosis como principio a partir del cual Granell va construyendo (él mismo considera a sus obras como "construcciones") 19 cada uno de los pilares de Granelandia. La más ostensible de las técnicas metamórficas; la más directamente perceptible, es de índole estética, interior a la propia forma, de parentesco cubista y se inscribe en la tradición moderna que tiene su origen en el collage y en el montaje cinematográfico: él lo llama "ensamblamiento" y podría definirse en tanto que agrupación de elementos heterogéneos individualizados que al unirse crean una unidad homogénea, tal y como sucede en la variedád de procedencias de los componentes de cualquiera de los personajes que pueblan sus escenarios. ${ }^{20}$

La segunda, la más genuinamente surrealista, es de orden animista y antropológico y se manifiesta bien en la antropomorfización de accidentes geográficos o geológicos (como en El secreto del rio Sil del año 74) bien en el zoo-antropomorfismo igualitario que se evidencia en los cuadros de cuatreros del año 72. La tercera, la más compleja y original, de orden conceptual y culturalista, es la raiz y médula de lo que hemos bautizado como "escritupintura" y atañe a la tradición específicamente española en la que se inserta su obra; la podemos llamar el bodegón teatral y tiene una doble cara: de una parte designa el tratamiento de los personajes humanos cual si se tratara de los alimentos

19. A una observación de Javier Ruiz (1994, p. 338) en tal sentido responde de modo afirmativo.

20. Este proceder es mucho más evidente en las esculturas que él prefiere llamar, no sin razón, "pintura en volumen". 
que suelen aparecer en los bodegones "a lo divino" del barroco español ${ }^{21}$ y de otra parte también se refiere al proceso de mutación - de pintura en teatro - que sufre su obra para dar así completa formulación a su poética y a su idioma. En este aspecto la deuda con Picasso - el que va desde los estudios para la Crucifixión a los dibujos de Une anatomie - es más que notable en cuanto a intención, idea motora y materialización de la estasis formal: la diferencia estriba en que Granell convierte dicha disposición en fundamento representacional y en concepto filosófico de toda su obra venidera, dualidad sobre la que van a girar los procedimientos lingüísticos empleados. $^{22}$

\section{Estética de la estasis}

Así pues sobre lo que podríamos llamar "principio-bodegón” y en su metamorfosis hacia lo teatral ( $¿$ no hay en la simple disposición zurbanaresca o de Sánchez Cótán de los objetos una "presentación" de los mismos cercana a la que tiene lugar dentro del escenario?) se articula, gira, todo el entramado imaginario sobre el que se sostiene Granelandia y que se materializa mediante los siguientes recursos técnicos:

1) Anulación de la superposición. La superposición entre las figuras se da en la realidad y como tal fue uno de los aspectos a imitar por los pintores a partir de Giotto para representar la profundidad, aunque para ello no respetaran la integridad de las figuras al verse obligados por fuerza a mutilarlas; ${ }^{23}$ Granell hace caso omiso pues desea tener entera libertad para que salgan "enteras", una prueba más de que su mundo persigue la totalidad y no entiende de fragmentaciones, cortes o disecciones provocadas por la razón (de cualquier forma esë carácter entero hay que entenderlo en un sentido muy relativó pues las manipulaciones y metamorfósis a las que somete a sus figuras son de tal

21. La idea de bodegón en relación con Granell fue anticipada por Javier Ruiz con las siguientes palabras: "Por esa naturaleza estática, por su asimetría compensada, por su estabilidad, todos tus cuadros tienen algo de bodegones". (1994, p.333).

22. Véase Picasso, 1991.

23. Desde"ese momento la mutilación del cuerpo se convierte en unó de los fundamentos representativos del realismo tal ý como es entendido por el racionalismo occidental, idea ahora más vigente que nunca y que parece haber sido descubierta como una de las novedades más importantes de los últimos años a partir de la obra, por ejemplo, de Bourgeois o Gober entre otros. Véase al respecto José M. Garcia-Cortés (1996). 
calibre que apenas recuerdan la apariencia de totalidad según ésta se entiende habitualmente); en cualquiera caso ese es la causa de su habitual separación unas de otras "como las frutas de un bodegón de Zurbarán”.(Ruiz, 1994,p. 334)

2) Sujección al plano y a la superficie. Como la pintura rupestre y la de los egipcios, y luego la de los beatos españoles, la pintura de Granell siempre, pero más particularmente en esta etapa, se adecúa a la forma más primitiva y genuina de representación esquemática de la imagen mental procedente de los procesos más habituales de percepción y de adquisición del conocimiento. Partiendo de premisas antinaturalistas y no racionales, de negación del espacio curvo y de las convenciones perspectivistas, se manifiesta como una imagen anticonvencional del mundo, respetuosa con sus propios presupuestos gráficos en cuanto mancha que rompe la monotonia de la superficie pero que no se atreve a sobresalir de las dos dimensiones. Es por lo tanto caligrafia de escritura y de pintura al únísono, manifestación directa del espíritu, totalmente inasible y que se proyecta o se plasma por impulsos de electroencefalograma actuantes en sus manos a modo de stylo o medium expresivo.

3) Tendencia hacia el fondo neutro. Anulado el terror vacui de la época precedente por una simplificación cada vez más acusada y a fin de destacar y aislar a la escena de su entorno, reducido siempre éste a la mínima expresión, recurre Granell al procedimiento, habitual en la pintura española de santos durante el Siglo de Oro, de ir neutralizando los fondos con un color uniforme, a veces solamente turbado por una falsa línea de divisoria que sólo sirve de referente entre un arriba y un abajo, casi nunca delimitadora del horizonte en el sentido de la profundidad. Dicha tendencia - más perceptible en su última etapa acentúa aún más el inmovilismo y la consideración de las figuras como objetos inanimados, pétreos, a los que parece referirse al comparar su estatismo con un puente: ${ }^{24}$

24. Textualmente: "Son tan estáticas como puede serlo un puente". (Ruiz, 1994, p. 340). Es curioso que exista un cuadro titulado La construcción del puente del año 1969, un cuadro en el que apenas se repara en él por apartarse temáticamente del resto de su obra y que creemos más importante de lo que parece precisamente por el simbolismo que encierra: el puente, en efecto, es sólido, inmóvil pero sus formas 


\section{El lugar imaginario: escena y barraca de feria}

Salvo algunas insinuaciones marítimas o terrestres que pueden remitirnos a la naturaleza, a lo que llamamos "mundo exterior", Granelandia es un lugar formado por espacios interiores, cerrados, no naturales, enmarcados por regla general en las partes superior e inferior por adornos o decoraciones que nos remiten a escenarios de representación, es decir a un mundo, evidentemente ficticio, relacionable con el espectáculo teatral (tal y como ha sido señalado por todos sus críticos, el último de los cuales Javier Navarro le acaba de dedicar una exposición monográfica de gran interés) (Zuvillaga, 1997) pero - y he aquí un matiz - no solamente teatral: nosotros le vemos también conexión (estamos hablando en cuanto al paisaje, al aspecto o a la apariencia del lugar) con el mundo de la barraca de feria, de esas de monigotes que hay que derribar usando de la puntería, habilidad o de la fuerza bruta para, a cambio de acertar en un cierto número de tiradas, conseguir un regalo ridículo cuyo valor siempre suele ser inferior al desembolso realizado. El espacio feérico es un espacio de simulación de la vida, de apartamiento mágico de la realidad insultante que te rodea: la inmersión en él transporta al individuo a la vivencia del sueño, de lo misterioso y de lo enigmático como si se tratara de la única realidad posible: es el espacio más inherente al niño, en el que siempre desearía habitar, al que siempre desea volver, en él todos sus sentidos se ponen en juego y en plenitud. Sabemos que su decorado es "de mentira", es de cartón-piedra, como el del teatro o el del cine, pero no obstante queremos que funcione como si fuera de verdad: lo que sucede - y he ahí su gran originalidad es que Granell combina a la perfección las referencias al espacio escénico - la tarima, la tramoya, las bambalinas - con el aspecto feérico que se deriva de los personajes, de las criaturas, que lo ocupan: funde en una unidad inédita - manifestación palpable del mestizaje - una doble tradición, la culta del teatro y la popular de la barraca del feriante o del guiñol. Pone en liza, en resumidas cuentas, dos tipos de ficción: la ficción

geométricas parecen desintegrarse o diluirse como el resto de las criaturas más maleables. Por otra parte el puente es lugar que une, que conecta dos partes para superar una dificultad: desde ese punto de vista este cuadro supondría, por su fecha, el paso, la evolución desde el paisaje mágico, magmático, sometido a metamorfosis continuas, hacia el nuevo paisaje característico de Granelandia. 
escénica y la ficción pictórica, superpuesta la una sobre la otra, con lo que metafóricamente Granell quiere indicarnos - creo - la imposibilidad del arte para hacernos creíbles sus mentiras (si la pintura podría-Picasso decía que "el artista debe saber el modo de convencer a los demás de la verdad de sus mentiras" 25 - cuando entra en liza lo teatral resulta del todo punto imposible dicho objetivo) o lo que es lo mismo que la naturaleza del arte, sus leyes nada tienen que ver con las de la vida.

Granelandia no tiene, pues, ni tan siquiera urbanismo (aunque sí, como veremos, urbanidad) sino que es una floración de escenarios que parecen haber brotado simultáneamente como por géneración espontánea con ausencia total de duración, de tiempo cronológico, y que nosotros creemos derivada de un pensamiento fundado en' lo que Kerrigan (1994,p. 340) bautizó como “imágenes en estado de transición instantánea";: causantes en nuestra opinión del aspecto irrisorio e inquietante a un tiempo que presentan sus pobladores.

\section{Pobladores, criaturas, sociedad}

Genéticamente - vale decir por orden de aparición - las criaturas que pueblan Granelandia parecen surgir de la boda del bandido de Córdoba, concretamente a partir de ese pescador de aguas tranquilas que construye un puente a través del cual va pasando a las criaturas híbridas del primer período y a los informes pobladores de los paisajes mágicos y geológicos del segundo para ir creando a los habitantes del nuevo microcosmos. Salvo en el principio, con los ya mentados protagonistas, y en el final de esta etapa de transición, con Uccello, su población parte de un principio dual, la pareja sexualmente diferenciada (aunque no necesariamente), núcleo y matriz de la sociedad graneladiense, tal y como se manifiesta en los años sucesivos en $E l$ amor del poeta Macías (aguada de 1968), El regalo (1972) o en El maestro... (1973) o de la pareja.indiferenciada y apenas reconoscible de El encuentro profundo de los reyes del mar (1970).

Común a todas ellas es la actuación en un plano que trasciende su mera presencia hacia la ejecución de fórmulas de cortesía social: regalar, felicitar, acudir a una cita, reflejo de una sociedad ideal, acaso

25. Realizadas en 1923 a Marius de Zayas. Cfr. Picasso, 1990, pág.27 
existente antaño o imaginada por las sagas góticas (la legendaria Camelot), basada en la ceremonia, el protocolo, la educación y la solemnidad, es decir una sociedad cortesana y teatralizada que tiene todos los visos de ser la éspañola de los Austrias en la que florece la cultura del Siglo de Oro', la de los Gracián, Cervantes, Quevedo, Velázquez, Calderón y Lope, ‘aquella que sigue siendo la referencia ineludible de nuestra historia y de nuestra idiosincrasia. ${ }^{26}$

Tras la pareja, el otro eje de la sociedad graneladiense es el grupo selecto (no más de cuatro personajes; cinco ya es muy raro) que, reunido, igualmente ejecuta actos sociales: conversa, analiza, dictamina o bien realiza alguna acción concreta. Es la función equilibradora del ágora en cuyo seno la individualidad, a partir del intercambio educado de opiniones, se enriquece y sirve para los fines que la propia colectividad se propone. En esta época de transición Los entomólogos escuchan el canto de los pájaros (1971) es el punto de partida de una riquísima fauna humanoide, que se mueve con boato, tranquilidad, ceremonia y solemnidad por los escenarios de Granelandia.

Pero no todo es bien, verdad y belleza en la sociedad ideal soñada por Granell: también existe el malvado como en los cuentos infantiles, al menos en un principio (aunque a partir del año 74 parece haber sido eliminado por completo de sus cónfines), personificado a trä̌és de las figuras del bandidò y del cuatrero: el primero, de raigambre cordobesa según vimos, acechando a una doncella (Joven temerosa de ser atacada por un bandido, 1968) o cruzando la fronterá tras"la felonía (Los bandidos cruzan la frontera, 1971) y los segundos consumando su robo en los éstablos bíblicos (Cuatreros de los establos déSalomón;'1972) seguramente tras haber esperado su oportunidad ocultos entre la maleza aprovechandò las sombras de'la noche (Cuatreros a lä luz de la lüna, 1972), son acaso los últimos exponentes de esos paisajes mágicos de la época anterior en los que aún cobran tributo las fuerzas negativas de la naturaleza a punto ya de ser vencidas por el espíritu pacifista de Uccello.

26. Su faceta como profesor de literatura española del Siglo de Oro, aspecto en el que ahora no podemos entrar, está en la raíz de esta inmersión panculturalista de su obra pictórica.' Para los aspectos teatrales implicados véase Zuvillaga, 1997, pp.18-35. 


\section{El orden lúdico: monigotes y muñecos}

Pero - y ahí reside uno de los aspectos más personales de Granell - los personajes de su sociedad, con ser importantes, selectos y asistir ellos mismos a su propia ceremonia, poseen un atributo original que neutraliza tan aparatoso fasto y los convierte en hechura de un orden lúdico superior en el que se insertan por obra y gracia de ese retorno exitoso a las raíces de la infancia. Y sabemos que es en ese mundo donde la acción repetitiva constante, producto de la aplicación de un cierto engranaje mecánico de que suele estar dotado el juguete - repetición que, por otra parte, es consustancial a la ceremonia solemne, a la cortesía y al protocolo cortesanos - convierte al personaje importante en ridículo, àl rey en plebeyo o simplemente a la figura bien compuesta, armoniosa y de apariencia exquisita en un simple monigote de feria o muñeco de guiñol. Este es el orden visual que ha recuperado Granell, a través de Granelandia, de la más absoluta déstrucción a causa del apabullante dominio del pensamiento artístico del adulto, lleno de seriedad, aburrimiento y dramátismo desde que Uccello precisamente no dejara libertad a las palomas (el cuadro de Granell es una ironía) por haber inventado el corsé de la perspectiva lineal.

Es en ese contraste de elementos, en ese elemento doble y en apariencia contrapuesto, culto y popular, de teatro y de barraca, de adulto y de niño, de libertad plena y de protocolo, de dinamismo y de estasis, todas las dicotomías a un tiempo siendo la misma cosa y sin oposición, donde cabe encuentrar la llave del cofre donde Granell, en el tabernáculo de Granelandia, esconde los secretos de su idioma literario y.pictórico a un tiempo (lo que hemos denominado escritupintura) y de su trascendental aportación, en calidad de pionero, a la poética del mestizaje, a la tan traída y llevada utopía de la fusión de culturas que conllevará sin duda la definitiva derrota de la razón y el triunfo de los nuevos bárbaros del sur y del oriente, que, como nuevos-niños, en su irracionalidad y salvajismo se impondrán a una cada vez más decadente civilización occidental aún empeñada en no salir del reino de las sombras. En el renacer que se atisba acaso Granelandia sea una prefiguración de la luz y Granell ya hecho niño ese nuevo guía bárbaro capaz de iluminar al nuevo humanismo que ha de acompañarle. 
Y como siempre sucede con Granell, hay que volver a transitar su isla al quedarse en el teclado (ya no en el tintero) la fundamental poética de lo grotesco que invade de principio a fin toda su obra. Otra vez será.

\section{Bibliografía}

BACHELARD, G. 1992. La poética del espacio. México: F.C.E.

BARTHES, R. 1982. Cámara lúcida. Barcelona: Gustavo Gili.

BAUDELAIRE, C.1988. "Exposición universal de 1855". Curiosidades estéticas. Ed. de Lorenzo Varela. Madrid: Júcar.

BENJAMIN, Walter.1987. Dirección única. Madrid: Alfaguara.

DURAND, Gilbert. 1983. Las estructuras antropológicas 'de lo imaginario. Madrid: Taurus.

FRANCASTEL. 1969. La figura y el lugar. Caracas: Monte Avila. GÁLLEGO, Julián. 1978. El cuadro dentro del cuadro. Madrid: Cátedra.

1984. Visión y símbolos en la pintura española del Siglo de Oro. Madrid: Cátedra.

GARCÍA-CORTÉS, José M. 1996. El cuerpo mutilado. Valencia: Generalitat.

GRANELL, E. 1986. “Granell por sí mismo". Catálogo La Coruña. Entrevista con César Antonio Molina. . 1989. "A la heuter d'uncri”. Granel -Catálogo Mapfre. . 1990. "El rito mecánico del Pájaro Pi". Catálogo Comunidad.

GUIGON, Emmanuel. 1996. Granell. Inventario del planeta. Santiago de Compostela: Fundación Granell.

HERRERA-NAVARRO, JAVIER. 1995. "Las raíces antropológicas e imaginarias del surrealismo de Eugenio F. Granell: 1942-1957". Goya, n'247-248 (julio-octubre), pp.65-77.

KERRIGAN.1994. "Un surrealista español en América". Coruña.

MOLINA, César A. 1990. "Los lugares y las formas". Catálogo Comunidad de Madrid, pp.65-73. 
OCAMPO, Estela. 1984. Apolo y la máscara. Barcelona: Icaria. 1989. El infinito en una hoja de papel. Barcelona: Icaria.

PICASSO, P. 1990. Picasso, poemas y declaraciones. Málaga: Fundación Picasso.

PIERRE, José. 1990. "Que trata del violín de Ingres...". Catálogo Comunidad de Madrid, pp.29-45.

POPPER, Frank. 1965. "Procèdés anciens et modernes d'indication du mouvement dans les arts plastiques". Sciences de l'art; II, pp.133-146.

1967. "Mouvement et space dans les arts plastiques". Sciences de l'art, IV, pp.137-145.

RUIZ, Javier. 1994. "El antropólogo de su memoria". Eugenio Granell. Colección Grandes Pintores. Ed. César A. Molina. Coruña: Disputación.

TARNAUD, Claude. 1964. Braises pour Granell. Paris: Phases.

ZUVILLAGA, Javier Navarro de. 1997. Granell y el teatro. Santiago de Compostela: Fundación Granell. 